\title{
A Tecnologia educacional e social aplicada à formação em saúde
}

\author{
Olga Maria Albuquerque ${ }^{1}$, Maria Hosana Conceição ${ }^{1}$, Maria Fernanda Melis ${ }^{1}$, \\ Felipe Albuquerque ${ }^{2}$, Cecile Rodrigues ${ }^{3}$ e Neusi Berbel ${ }^{4}$ \\ olgamaria@unb.br; hosanac@unb.br; mfernanda.melis@gmail.com; \\ felipe.moreira.albuquerque@usp.br; cecile_rodrigues@hotmail.com; \\ neusiberbel@gmail.com \\ ${ }^{1}$ Universidade de Brasília (UnB), Brasília/DF, Brasil \\ ${ }^{2}$ Escola Politécnica da Universidade de São Paulo (USP), São Paulo, Brasil \\ ${ }^{3}$ Gestão em Saúde UPE/UAB, Brasil \\ ${ }^{4}$ Professora aposentada da Universidade Estadual de Londrina, Paraná/PR, Brasil
}

DOI: 10.17013/risti.38.92-107

\begin{abstract}
Resumo: Esta pesquisa focaliza, por meio do estudo de caso, mudanças no pensamento sobre o ensino superior, além da necessidade de formação de profissionais críticos e com capacidade de análise da realidade social. Seu objetivo foi analisar a percepção de estudantes do curso de graduação em Saúde Coletiva da Faculdade de Ceilândia-Universidade de Brasília, sobre a adoção de Tecnologia Educacional e Social no ensino-aprendizagem na disciplina Atenção Primária à Saúde (APS). A formação do Sanitarista mediada pela ação-reflexão-ação estimulou a identificação crescente dos estudantes com a futura profissão, desvelou processos multifacetados de aprendizagem e a percepção da complexidade humana envolvida nos serviços de APS. O uso da Tecnologia Digital de Informação e Comunicação no trabalho de campo contribuiu para aproximação entre a Universidade e o serviço de saúde. Concluiu-se que a articulação da disciplina APS à prática da APS implica boa comunicação entre diferentes instituições/atores sociais para alcançarem objetivos pedagógicos comuns.
\end{abstract}

Palavras-chave: Tecnologia da Informação e Comunicação; Tecnologia Educacional; Formação Profissional em Saúde; Atenção Primária à Saúde.

\section{Social and educational technologies applied in health training}

Abstract: This research focuses, through the case study, changes regarding higher education thinking, as well as the need for developing critical professionals capable of social reality analysis. Its aim is to analyze Faculdade de Ceilandia - Universidade de Brasília's public health undergraduates' perception of Social and Educational Technology use in teaching/learning at Primary Health Care (PHC). Sanitarists qualification guided by action-reflection-action process stimulated their growing identification with their future profession, revealed multifaceted learning processes 
and human complexity involved in PHC services. The use of Digital Information and Communication Technologies in fieldwork contributed to connecting the university to the health services. It is concluded that articulating the subject PHC to the practice of $\mathrm{PHC}$ requires good communication between different institutions/ social actors to achieve common pedagogical goals.

Keywords: Information Technology; Educational Technology; Health Human Resource Training; Primary Health Care.

\section{Introdução}

O papel de tomar decisões sobre o quê e como ensinar, considerando quem, por quê, quando e onde se ensina, caracteriza o trabalho do professor. O sentido desse trabalho se sintetiza no termo ensino, para o que muito contribuem os conhecimentos e as elaborações da didática. Seu foco, então, não são apenas métodos e técnicas de ensino/ aprendizagem, nem tampouco uma simples adesão a novas tecnologias ou aumento de produtividade no trabalho. A questão central reside em colocar o ensino a serviço do desenvolvimento pessoal e crítico do(a) estudante e da sociedade (Sant'Anna \& Menegolla, 1989).

Esses elementos encontram-se diretamente associados à formação do professor e muitas deficiências têm sido reconhecidas nesse campo. A crença de que para ser um bom professor bastariam sólidos conhecimentos na disciplina que leciona e ter uma boa comunicação não é mais aceitável. Estudos pedagógicos, realizados com estudantes universitários, revelam que uma das maiores críticas ao ensino tem sido a "falta de didática dos professores" (Gil, 2008, p. 01).

Em tais circunstâncias, adquire relevância a reflexão sobre o papel do professor e a contextualização de suas estratégias didáticas, especialmente no cenário da formação em saúde pública, visto que o Sanitarista constitui um novo ofício em saúde em fase de consolidação de sua identidade profissional (Silva \& Pinto, 2013; Albuquerque et al., 2018; Silva, Pinto \& Teixeira, 2018). De acordo com Katajavouri, Lindblom-Ylänne \& Hirovonen (2006), o fortalecimento dessa identidade profissional resulta, também, da aplicação dos conhecimentos teóricos adquiridos e vivenciados em situações reais de trabalho.

Os estudos de Guile \& Evans (2010) e Vendruscolo, Prado \& Kleba (2016) versam sobre a relevância do trânsito entre teoria/prática em ambiente institucional. Outros pesquisadores ressaltam as facetas desse ensino profissional ao descreverem a forma pela qual o ensino e a aprendizagem, associados ao local de trabalho, fomentam o mimetismo do exercício da profissão. Essa realidade vivenciada no cenário de prática delineia a natureza da aprendizagem, englobando a contextualização do conteúdo do curso e as abordagens pedagógicas. E, por conseguinte, a inserção no local de trabalho garante ao estudante a compreensão mais clara do que está sendo estudado (McCrone, O’Beirne, Sims \& Taylor, 2015).

A apropriação do conhecimento prático ocorre por meio da participação dos aprendentes em um campo de trabalho. Ali eles podem aplicar e, até mesmo questionar, a teoria 
adotada. Por essa razão é vital a parceria pedagógica entre a universidade e os serviços que oferecem Atenção Primária à Saúde (APS). O processo de aprendizagem nesse cenário pode favorecer uma interação potencialmente construtiva entre a teoria e a prática. Tal parceria é o fundamento sobre o qual a teoria debatida em sala passa a fazer sentido e cria um ambiente favorável ao ensino-aprendizagem (Albuquerque et al., 2020, p. 810).

Tal dinâmica de aprendizagem relaciona-se ao conceito de tecnologia educacional descrita por Januszewski \& Molenda (2008, p. 04) como "o estudo e a prática ética de facilitar a aprendizagem e melhorar o desempenho (performance) por intermédio da criação, do uso e do gerenciamento apropriado de processos e recursos tecnológicos”. Nos anos sessenta a concepção de tecnologia educacional focalizava o manejo do "processo de aprendizado". Atualmente, a ênfase é colocada em "facilitar a aprendizagem, fornecendo "o espaço do problema e as ferramentas cognitivas para explorá-lo [...] em ambientes imersivos para apoiar o aprendizado" (Albuquerque et al., 2020, p. 810).

Para estes autores o conjunto de recursos tecnológicos se expandiu com a multiplicidade das inovações tecnológicas disponíveis e a elaboração de um entendimento sobre como essas ferramentas tecnológicas podem ajudar a orientar os alunos. Os recursos pedagógicos a que se referem Januszewski \& Molenda, (2008, p. 04) incluem pessoas, ferramentas, tecnologias e materiais projetados para, repetindo, orientar os alunos. Abrangem, também, os sistemas de Tecnologia de Informação e Comunicação, de recursos da comunidade, como bibliotecas, zoológicos, museus e pessoas com conhecimento ou experiência especial. Ao mesmo tempo, envolvem a mídia digital, como, por exemplo, os CD-ROM, websites e WebQuests, e sistemas de suporte a desempenho eletrônico. $\mathrm{E}$, além disso, englobam a mídia analógica, como livros e outros materiais impressos, gravações de vídeo e outros materiais audiovisuais tradicionais (Januszewski \& Molenda, 2008, tradução nossa).

Mais recentemente, esses recursos pedagógicos vêm sendo denominados Tecnologia Digital de Informação e Comunicação (TDIC) (Baranauskas \& Valente, 2013). Tal concepção mais contemporânea de TDIC é descrita por Costa, Duqueviz e Pedroza (2015) como o conjunto de tecnologias digitais representadas pelo computador, tablet, celular, smartphone e qualquer outro dispositivo que permita navegação em ambiente multimídia da internet. Sua utilização está se consolidando na "aprendizagem dos nativos digitais que passa a ser mediada pelas novas tecnologias, entendidas como instrumentos do nicho cultural em que essas pessoas operam" (Lalueza, Crespo \& Camps, 2010, p. 608).

A Política Nacional de Atenção Básica (Brasil, 2017) define a Atenção Básica (AB) como "o conjunto de ações de saúde individuais, familiares e coletivas que envolvem promocão, prevencão, protecão, diagnóstico, tratamento, reabilitacão, reducão de danos, cuidados paliativos e vigilância em saúde, desenvolvida por meio de práticas de cuidado integrado e gestão qualificada, realizada com equipe multiprofissional e dirigida à populacão em território definido, sobre as quais as equipes assumem responsabilidade sanitária" (Brasil, 2017).

Desde 2017 a Estratégia Saúde da Família (ESF) passou a constituir a estratégia de orientação do modelo de Atenção Primária à Saúde (APS) consubstanciada na Política de Atenção Primária à Saúde (PAPS) do Distrito Federal/Brasília (Distrito Federal, 2017). As diretrizes para sua implementação incluem: o acolhimento, a classificação de 
risco, a resolutividade, a territorialização, a adscrição de clientela, a garantia de acesso e a ordenação da rede de saúde.

Uma das diretrizes da PAPS-DF (Distrito Federal, 2017, p o3) se configura na "adscrição da clientela". Sua operacionalização implica no "cadastramento e no acompanhamento da população sob sua responsabilidade, por intermédio de ações na unidade de saúde, na comunidade ou em visitas domiciliares, utilizando as informações para o planejamento de seu trabalho e para o desencadeamento de ações de outros níveis da gestão" pelas equipes Saúde da Família (eSF). Essa Portaria especifica o quantitativo de pessoas cadastradas por território de saúde que constitui a base para um repertório de indicadores de produção das equipes Saúde da Família (eSF).

O conjunto de diretrizes instituídos na PAPS (2017) está em consonância com a Constituição da República Federativa do Brasil (Brasil, 1988) e com outros dispositivos jurídicos que regem a organização do Sistema Único de Saúde (SUS): a Lei 8.o80 (Brasil, 1990) e a Portaria de Consolidação n 2 (Brasil, 2017) cujo Anexo XXII institui a Política Nacional de Atenção Básica (Brasil, 2017).

Esse ato administrativo do Ministério da Saúde (Brasil, 2017) apresenta uma novidade que fortalece a identidade do Sanitarista ao prever a inclusão do "Gerente de Atenção Básica (GAB)" como um dos profissionais a serem contratados nesse ponto de atenção à Saúde. Uma das atribuições deste GAB é: "participar e orientar o processo de territorialização, diagnóstico situacional, planejamento e programação das equipes, avaliando resultados e propondo estratégias para o alcance de metas de saúde, junto aos demais profissionais" (Brasil, 2017).

A presente pesquisa se situa no contexto de mudanças no pensamento sobre a formação no ensino superior, que aponta para a necessidade de formação de profissionais críticos e com capacidade de análise da realidade social. Essa é a razão pela qual os percursos metodológicos, trilhados com esse propósito, pelos processos de ensino-aprendizagem estão sendo aqui analisados (Albuquerque et al., 2020).

Uma vez que a graduação em Saúde Coletiva (SC) é um curso em fase de consolidação, a pergunta a ser respondida pelo estudo é: quais características de Tecnologia Educacional e Social (TES) foram reconhecidas pelos estudantes como mais relevantes ao ensinoaprendizagem na disciplina Atenção Primária à Saúde? (Albuquerque et al., 2020).

O objetivo do estudo foi analisar a percepção dos estudantes do curso de graduação em Saúde Coletiva, sobre a adoção de TES no ensino-aprendizagem na disciplina de Atenção Primária à Saúde (APS) (Albuquerque et al., 2020).

\section{Metodologia}

Adotou-se a pesquisa qualitativa do tipo estudo de caso, cuja principal característica é ser "uma investigação empírica que pesquisa um fenômeno contemporâneo dentro de seu contexto da vida real, especialmente quando os limites entre o fenômeno e o contexto não estão claramente definidos" [...] ; "enfrenta uma situação tecnicamente única em que haverá muito mais variáveis de interesse do que pontos de dados e, como resultado, baseia-se em várias fontes de evidência e beneficia-se do desenvolvimento 
prévio de proposições teóricas para conduzir a coleta e análise dos dados" (Yin, 2005, pp. 32-33 apud Albuquerque et al., 2020, p. 811).

Para Stake (200o, p. 445, tradução nossa) o que caracteriza um estudo de caso intrínseco é o fato que "ilustra um caso particular e possibilita o entendimento mais profundo de um caso específico”. Particularmente nesse estudo, é também heurístico em virtude de adicionar compreensão à prática pedagógica, ampliando a experiência da professora ou corroborando aspectos já conhecidos de sua prática. Nessa pesquisa se delineou um conjunto de ações intencionais de ensino-aprendizagem promovidas em sala de aula e no cenário de prática institucional, que se desenvolveram nos semestres 2018/2, 2019/1 e 2019/2 com 67 estudantes (Albuquerque et al., 2020).

A disciplina APS, de 40 horas, é ofertada no quarto semestre do curso de graduação em Saúde Coletiva na Faculdade de Ceilândia/Universidade de Brasília (FCE/UnB). Vinha sendo ministrada na modalidade presencial, sem interrupção, desde 2014 até o segundo semestre de 2019 com as mesmas características metodológicas. Seus propósitos eram buscar a convergência da teoria com a prática; promover a interlocução com egressos exercendo função de Sanitaristas nos serviços de saúde, bem como operacionalizar a “indissociabilidade entre ensino, pesquisa e extensão". Para isso, a disciplina está integrada ao Projeto de Extensão de Ação Contínua "Tecnologia Educacional e Social como dinamizadoras na formação em saúde".

Nas primeiras edições da disciplina APS, os estudantes visitavam as UBS para confrontar alguns aspectos de implementação da PAPS-DF (2017) com a realidade existente naqueles cenários de práticas. Em seguida, eles desenvolviam a tecnologia social num processo de construção coletiva em parceria com as pessoas do lugar para operarem algum tipo de mudança. Além disso, eles colaboravam nas homenagens aos profissionais de Enfermagem no seu dia comemorativo e no desenvolvimento de ações para celebrar o Outubro Rosa na UBS 8.

Desde a conversão do modelo de atenção, as parcerias firmadas com a APS em Ceilândia passaram a incluir também as visitas aos residentes das microáreas. Ali eles interagiam com seus moradores e preenchiam seus cadastros para registrarem as famílias adscritas àquela UBS. Nessa atividade eles eram acompanhados de perto pelas ACS. Uma regra básica de comportamento para atuar nesse cenário é o respeito devido a cada uma dessas pessoas: as/os ACS, os usuários com quem entram em contato e os outros servidores da UBS (Albuquerque et al., 2020).

A PAPS-DF (2017) instituiu a mudança do modelo tradicional de APS em ESF por meio da Portaria 77 (Distrito Federal, 2017). No mesmo ano, a Portaria 78 (Distrito Federal, 2017) ofereceu aos profissionais de saúde a possibilidade de realocação na APS ou em outros pontos da atenção à saúde. Essa operação, amparada pelas Portarias, proporcionou “a composição de 442 equipes de Saúde da Família (eSF) e a ampliação da cobertura populacional para 69,1\%” (Corrêa et al., 2019, p. 2037).

A Secretaria Estadual de Saúde - DF reconhece que o maior desafio enfrentado para essa ampliação é a carência de Agentes Comunitários de Saúde (ACS) para atuarem nas eSF (Corrêa et al., 2019, p. 2037). Essa circunstância criou as condições para uma parceria mais substancial da disciplina APS com o serviço de saúde do DF. 
Na sequência desse processo de trabalho e supervisionados pelos profissionais do setor de Vigilância em Saúde, os estudantes utilizavam tecnologia digital ao inserir no Sistema de Informação da Atenção Básica (SISAB) os dados coletados por eles no cadastramento da população adscrita. A operacionalização no SISAB ocorreu através "da estratégia do Departamento de Atenção Básica/Secretaria de Atenção à Saúde do Ministério da Saúde denominada e-SUS Atenção Básica (e-SUS AB)” (Brasil, 2019). Essa estratégia permite a interoperabilidade da plataforma SISAB com os sistemas de informacão em saúde no âmbito do SUS nas esferas Municipal, Distrital, Estadual e Federal.

Esta pesquisa utilizou TES específicas como ferramentas pedagógicas para uma formação profissional contextualizada e inserida nas diferentes atividades na APS em Ceilândia. A efetivação dessas TES consistiu em: leituras e sínteses dos textos sobre APS; apresentação da síntese destes artigos científicos que adotaram práticas interrelacionadas com a APS com base em critérios de avaliação pré-definidos e em sua vivência na APS; apropriação da legislação vigente no confronto com sua materialização no cenário de práticas para refletirem a partir das vivências no campo da APS; interação com os moradores da microárea e com servidores da UBS; e, interlocução dos estudantes com gestores e egressos que já atuam como Sanitaristas (Albuquerque et al., 2020).

Outra iniciativa recorrente em todos os semestres de desenvolvimento da disciplina APS foram as rodas de conversa com gestores de APS. Elas promoveram a aproximação dos estudantes à prática da profissão de Sanitarista e se materializaram na interlocução com gestores em exercício na APS e com os egressos do curso de Saúde Coletiva. Ao longo do semestre cada um dos grupos elaborava uma pergunta para os egressos e para os gestores que participariam das rodas de conversa. Ao apresentarem as sínteses dos artigos eles submetiam essa pergunta à avaliação de seus pares. Na ocasião, avaliava-se a clareza do questionamento efetuado e optava-se por perguntas abertas que favorecessem amplitude de resposta com explanação irrestrita das atividades desenvolvidas no dia a dia dos serviços de APS.

Essas perguntas guiaram o diálogo nas 5 rodas de conversa com os gestores e os egressos de Saúde Coletiva, que se desenvolveram na sala de aula, durante as aulas de 2 horas, contando com uma média de 22 estudantes. Observou-se predominância do gênero feminino que representava dois terços dos presentes. A professora moderou essas conversas coletivas, que partiam das questões elaboradas por eles, apoiadas nas leituras e em suas vivências nas UBS.

No término de cada semestre os estudantes avaliavam a disciplina APS respondendo, anonimamente, às seguintes perguntas: que contribuição a Atenção Primária em Saúde trouxe para o seu processo de formação pessoal? que contribuição a Atenção Primária em Saúde trouxe para o seu processo de formação como profissional de saúde? que contribuição a Atenção Primária em Saúde trouxe na sua relação com os demais sujeitos da sociedade? Todas as vezes que se aplicava essa avaliação, a professora se ausentava da sala para garantir que os estudantes manifestassem seu pensamento de forma espontânea. Suas respostas constituíram o corpus sobre o qual efetuou-se a análise de conteúdo. 
A regra de recorte na análise de conteúdo utilizou o tema representado pelas unidades de registro. Isto é, pela "unidade de significação que se liberta naturalmente de um texto analisado segundo certos critérios relativos à teoria que define o tema como "uma afirmação acerca de um assunto [...] uma frase, ou uma frase composta, habitualmente um resumo ou uma frase condensada" (Bardin, 2011 p. 35). No caso específico dessa pesquisa a adoção da unidade de registro é condizente com o propósito de investigar as "motivações de opiniões, de atitudes, de valores, de crenças, de tendências, etc.” (Bardin, 2011, p. 135). De fato, a avaliação da disciplina APS foi desenhada com vistas ao seu melhoramento continuado, tomando por base o ângulo de visão dos estudantes sobre a mesma.

Uma das etapas de sistematização dos dados gerados com esse estudo consistiu na transcrição das palavras e das frases, que se constituíram nas unidades de registro. Depois na leitura flutuante, que propiciou a formulação de hipóteses provisórias e o conjunto de categorias inicialmente identificadas. Na sequência, as leituras reiteradas nortearam a codificação e o agrupamento dos dados em núcleos de sentido. A triangulação final contemplou a teoria de referência empregada no plano do estudo e o material recolhido nas avaliações efetuadas pelos estudantes. Nos resultados são apresentadas essas citações diretas originadas dos dados, que passaram a compor as unidades de registro marcadas pela letra "E” de estudante e do número vinculado a ele.

\section{Resultados}

A implantação do modelo de APS decorrente da conversão do modelo tradicional de APS em ESF (Corrêa et al., 2019) começou em 2016. No ano seguinte, o artigo primeiro da Portaria 78 (Distrito Federal, 2017) estipulava que: “As Unidades Básicas de Saúde (UBS) serão convertidas progressivamente para o modelo de Estratégia Saúde da Família, priorizando-se, no processo de conversão, as áreas de maior vulnerabilidade social”.

Atendendo a essa determinação, desde o início do semestre letivo, os estudantes realizavam as atividades de visita às UBS para conhecer traços da realidade existente e confrontá-los com aspectos teóricos que fundamentaram a implementação da PAPS-DF (Distrito Federal, 2017).

Ao final de todas as atividades realizadas, como já descritas e avaliadas pelos estudantes, e da leitura e releitura do corpus da pesquisa, emergiram sentidos relativos às estratégias de TES adotadas no processo ensino-aprendizagem da APS categorizados em 3 núcleos: a) a TES no processo de formação da identidade profissional; b) a importância da TES para a percepção do nexo entre teoria e prática na APS; c) a importância da TES na interação entre estudantes, gestores e usuários de UBS, que são apresentados e analisados a seguir.

\subsection{Tecnologia educacional e social no processo de formação da identidade profissional}

O conjunto de frases salientadas nas avaliações ressalta a relevância da TES para consolidar a autopercepção dos estudantes como futuros profissionais: "mais capacitada 
para lidar com problemas" (E1), "sensata e realista" (E2), "atento às necessidades da população" (E3), "capaz de enfrentar dificuldades" (E4), [preparado para] "exercer meu papel como gestor" (E5), (E6).

Alguns estudantes expressaram sua percepção sobre o uso das estratégias de TES que foram desenvolvidas na disciplina de modo bastante significativo, como E6, por exemplo: "a APS abriu meus olhos ao meu futuro campo de atuação [...] as dificuldades que poderei enfrentar e como resolvê-las". Outro estudante (E7) valorizou a disciplina por ter-lhe proporcionado uma "visão mais ampliada do Sistema de Saúde, especificamente a Atenção Básica, com um olhar de profissional”.

Ao mesmo tempo, ângulos da formação foram ressaltados por E8: "A [disciplina] APS foi de 'super' contribuição para minha formação em Saúde Coletiva, os conhecimentos das leis e portarias trouxeram um conhecimento mais profundo para uma gestão qualificada e de competência nas Unidades de Saúde”. Outra manifestação mostra uma identificação forte com a disciplina: "A APS trouxe para o meu processo de formação pessoal uma paixão pela área, uma auto-descoberta como área de atuação, me fez enxergar como nós profissionais de Saúde Coletiva somos fundamentais na ponta, na prestação de serviços" (E9). Existem momentos em que os estudantes se referem à disciplina APS e, em outros, eles se reportam à APS. O contato com a Atenção Primária à Saúde propiciado pela disciplina tem esse poder de dar sentido à profissão para a qual se preparam. A PAPS-DF (Distrito Federal, 2017) estipula que a "porta de entrada" e o "contato preferencial dos usuários com o sistema de saúde" ocorra neste ponto da atenção à saúde.

Mesmo com a dificuldade representada pela leitura inusual da legislação, um estudante assume: "pude aprender melhor sobre a APS e como aplicar esses conhecimentos na UBS, na gestão, intervir segundo as Portarias" (E10). Outro estudante se imagina exercendo sua profissão no futuro na APS e a valoriza: "foi incrível, eu finalmente entendi as possibilidades de meu futuro como gestora, a apropriação do conhecimento [...] essa disciplina me inspira a ser a melhor sanitarista possível" (E12). O conhecimento de um campo concreto de trabalho do Sanitarista proporciona aos estudantes desenvolveram uma identificação crescente com a futura profissão.

As discussões em sala de aula, proporcionadas por diferentes TES adotadas na disciplina APS possibilitaram focalizar os principais desafios a serem enfrentados pelos estudantes em sua futura profissão e os estimularam a adotarem diferentes posicionamentos em busca da melhor atuação profissional possível. As avaliações descritas neste tópico revelam as consequências da dinâmica adotada na disciplina.

O conjunto de enunciados dos estudantes de Saúde Coletiva corroboram o estudo de Sisson (2009). Nessa pesquisa os participantes apontam a identidade profissional e a aquisição de valores sociais como resultado da prática vivenciada e realizada. Os estudantes da disciplina APS também revelaram aquisições e apreciações nessa direção, como por exemplo E13, ao registrar: "aprendi a me colocar no lugar do tomador de decisão e analisar a situação como um profissional”. Para outros, as visitas às UBS suscitaram a identificação com a profissão apoiada na "legislação para a tomada de 
decisão" (E12); "me fez pensar como gestor" (E14), "como profissional de saúde na APS, como tomador de decisão" (E15).

Da mesma forma, outro estudante afirma que "A APS trouxe uma perspectiva de conhecimento na função de fazer, delegar e de gestor de saúde" (E16). Esses aspectos, basilares nas atividades desenvolvidas, mesmo não destacadas de igual forma por todos, desvelam ganhos significativos adquiridos pelos acadêmicos na disciplina. Essa reflexão é consistente com o estudo de Katajavouri, Lindblom-Ylänne \& Hirovonen (2006) no qual os estudantes alegaram que o período de prática os preparava para a vida profissional que lhes permitiria trabalhar depois da formatura.

As atividades desenvolvidas em sala de aula constituíram um desafio duplicado: impulso para os estudantes se apropriarem dos principais conceitos que dão sustentação à APS e a compreensão da lógica da legislação estruturante do modelo da APS, a PAPS-DF (Distrito Federal, 2017) e a Política Nacional de Atenção Básica (Brasil, 2017), como guia na tomada de decisão. Ao longo desse texto observa-se que alguns estudantes empregam o termo Atenção Básica (AB). Isso acontece porque ambos os atos administrativos, a PAPS-DF (Distrito Federal, 2017) e a PNAB (Brasil, 2017), admitem os 2 termos: AB e APS, para designar este ponto da atenção em saúde (Albuquerque et al., 2020).

"Como profissional devo sempre ser pautada pelos regulamentos [...] ter esperteza e "feeling" na tomada de decisão, além de conhecer muito bem o meu objeto de trabalho: teoria + senso crítico + vínculo" (E11). A aquisição dos saberes profissionais agrupou à teoria, a legislação, as práticas reflexivas e a sinergia com o trabalho proporcionado pelas vivências nesse itinerário formativo. Segundo Vendruscolo, Silva \& Silva (2017, p. 258) a "interdependência entre prática e teoria e a integracão às instituicões, por meio do envolvimento efetivo dos atores, é condicão fundamental para a adequacão do processo de formacão às necessidades do SUS".

Os fragmentos expressivos dos estudantes desvelaram que "é no encontro entre o mundo da formação e o mundo do trabalho que o aprender e o ensinar se incorporam ao cotidiano" (Ramos, Barros \& Ferraço, 2004). O Projeto Político Pedagógico [PPP] (Brasil, 2019) do curso de SC inclui 4 eixos: o modo de vida, os sistemas biológicos, as especificidades do fazer em SC e os cenários e práticas em SC. O eixo que aborda as "especificidades do fazer em SC enfatiza aqueles aspectos, conteúdos e abordagens, voltados à qualificacão da acão dos estudantes nas questões [...] implicadas na prática de estruturacão, organizacão e gestão da atencão em saúde e na consolidacão do Sistema Único de Saúde.” A perspectiva aportada pelas avaliações dos estudantes indica uma confluência aos preceitos registrados no PPP (Brasil, 2019).

É possível que a prática pedagógica aponte, no futuro, para a necessidade de incorporações de novos eixos pedagógicos ao curso, como por exemplo, um eixo filosófico, a fim de oportunizar um aprofundamento no pensamento ético-epistemológico, necessário à tomada de decisão gerencial e de pesquisa na área.

\subsection{Importância da TES para a percepção do nexo entre teoria/prática na APS}

A atuação dos estudantes no campo criou as condições para eles procederem ao cadastramento da população na área adscrita da ESF e, a seguir, à digitação dos dados 
no SISAB (Fernandes e Tareco, 2016). Adotadas como recurso pedagógico na formação acadêmica para atuação na APS, as TDIC's utilizadas no trabalho de campo e no ensino contribuíram para a aproximação entre a Universidade e o serviço de saúde. Isso parece ter sido importante para a interligação entre teoria e prática nos cenários de aprendizagem propostos (Albuquerque et al., 2020).

Ao mencionarem o trabalho de campo encontram-se manifestações como: "conhecimento e vivência da realidade da APS [...] vivência na UBS como prática fundamental" (E17), a "aplicação da teoria na prática" (E18), o "vínculo entre teoria e prática" (E19) e a compreensão de "como funciona na teoria e na prática a APS" (E15). Encontramse também outras demonstrações da existência de uma relação frutífera entre teoria e prática na formação profissional. Tudo isso enfatiza a importância da colaboração ensino-serviço, afastando a dissociação entre a teoria e a prática. Essas percepções dos estudantes revelam a concretização de incisos da Constituição Federal (Brasil, 1988) e da Lei 8.08o (Brasil, 1990) que estabelecem o ordenamento "da formação de recursos humanos na área da saúde" como competência e campo de atuação do SUS.

Uma das expressões dos estudantes é condizente com o eixo do PPP (Brasil, 2019) que preconiza o ensino atrelado aos "cenários e práticas em Saúde Coletiva": " $A$ [disciplina] APS me deu uma visão prática do que acontece na vida real" (E20). Isso está em consonância com o estudo de Lave (1993 p. 30, tradução nossa) cujos resultados afirmam que "o conhecimento prático é adquirido trabalhando e participando de um ambiente de trabalho onde a teoria possa ser aplicada”.

"A [disciplina] APS aprofundou meus conhecimentos de APS e também nos colocou como gestores ao nos dar leis e documentos que regem nossa atuação e fazendo a conexão da teoria com a prática" (E11). Nessa frase do estudante é possível perceber a relevância das Portarias que guiam a operacionalização e a tomada de decisão do gestor. Nesse sentido a atuação do gestor é mediada por 'variáveis políticas' que se materializam em sua prática diária por meio da atividade relacional e da aplicação dos conhecimentos conjugados aos "saberes e práticas de gestão" no cotidiano dos serviços.

A atuação do gestor se configura no exercício das funções gestoras. Os autores Matta \& Pontes (2007, p. 148), definem essas funções gestoras "como um conjunto articulado de saberes e práticas de gestão necessárias para a implementação de políticas de saúde e que devem ser exercidas de forma coerente com os princípios do sistema público de saúde e da gestão pública”.

"Por fazer a ligação da teoria com a prática [a disciplina APS] me fez enxergar necessidades e ter um olhar mais amplo em relação à sociedade" (E9). Os resultados da pesquisa de Pizzinato et al. (2012, p. 176) assinalam a conexão entre os processos de ensino e o fornecimento de serviços como disparadores na formação dos estudantes. Essa integração de agentes, ações e ferramentas desencadeiam a vivência dos "desafios de materialização dos princípios do SUS na atencão básica em saúde, estimulando a formação de recursos humanos para atuação na rede de serviços do sistema”.

"Trouxe coisas importantes como a experiência de vivenciar a teoria com a prática e como nossa formação é importante para a APS. Uma das poucas disciplinas que faz os alunos vivenciarem teoria e prática" (E21). Na abordagem pedagógica adotada na disciplina APS os saberes foram estimulados/mobilizados através da elaboração de 
sínteses dos artigos voltados à atuação na APS. Os critérios de avaliação definidos no plano de ensino instigavam o nexo com aspectos de operacionalização das Portarias PAPS-DF (Distrito Federal, 2017) e PNAB (Brasil, 2017) (Albuquerque et al., 2020).

Os resultados deste estudo são consistentes com a pesquisa de Katajavouri, LindblomYlänne \& Hirovonen (2006). Nele a atividade desenvolvida pelos estudantes no ambiente de trabalho desencadeou a vinculação aos saberes teóricos, bem como a percepção da coerência existente na ligação entre os aspectos práticos e teóricos.

\subsection{Importância da TES na interação entre estudantes, gestores e usuários de UBS}

Muitas palavras remontam ao relacionamento, à sinergia e à interação construídas pelos estudantes com os sujeitos encontrados no trabalho de campo: "diálogo" (E4), "importância do trabalho em equipe" (E6, E19, E20, E22, E23), "vínculo" (E11), "responsabilidade” (E17, E18, E19, E23 ), “empatia” (E15, E17, E18, E20, E21, E24, E25, E26, E29, E30), “compreensão” (E26), "respeito” (E28), "esperança, compaixão” (E30).

A atuação dos estudantes no cenário real de uma UBS vivenciada por eles no campo de práticas motivou importantes reflexões sobre questões relativas à complexidade humana envolvida nesse local de trabalho, como indica esta frase: "com as saídas de campo pude ter uma melhor relação com os demais sujeitos da sociedade, saber ouvi-los e ajudá-los no que for necessário" (E31). Isso permitiu mobilizar habilidades como a cooperação, a interação entre sujeitos, além de repensar a importância das relações interpessoais na adaptação aos cenários e às situações existentes em contextos de atuação coletiva (Albuquerque et al., 2020).

Eis uma amostra de como a TES influenciou a formação dos futuros profissionais e cidadãos. Na disciplina APS os estudantes não só atuam em equipes, como também, enquanto componentes de equipes, relacionam-se com sujeitos da sociedade, aprendendo a ouvi-los para perceber suas necessidades.

A proximidade ao cotidiano do trabalho das equipes Saúde da Família propiciou participação ativa dos sujeitos envolvidos na dinâmica das relações sociais e as circunstâncias representadas pela interculturalidade do trabalho em equipe: " $a$ disciplina [APS] trouxe uma evolução, pois fui desenvolvendo a capacidade de construir relacionamentos interpessoais e aprendendo a lidar com as pessoas" (E32).

Aprendendo a viver/atuar com o outro, o participante da equipe se descobre também. Descobre ainda, em contato com a realidade de saúde no campo, como atuam outros profissionais em relação à mesma população. "A [disciplina] APS me trouxe a capacidade de compreender os profissionais de saúde, como 'funciona' seus processos de tomada de decisão para lidar com as dificuldades e demandas da população" (E15). E ainda [ajudou a] "me tornar uma melhor profissional, com mais habilidade de escuta, sendo mais humanizada e acolhedora, com melhor compreensão dos processos sociais e do ambiente no qual estarei inserida" (E33). Outra habilidade adquirida pelos estudantes se refere ao cuidado em saúde entremeado pela cooperação e o respeito aos usuários dos serviços. 
"A ida à UBS me fez ter contato com uma realidade que eu ainda não conhecia. Me ajudou com valores pessoais como respeito, empatia, solidariedade e 'prestatividade'. Valores que ajudam muito nas relações sociais" (E34). Esses valores apontados pelos estudantes possibilitam o desenvolvimento de atitudes para se inserir nos coletivos de trabalho e constituem referência ética na interface com a população.

Para atuar na gestão dos serviços de saúde o trabalho do Sanitarista se estrutura na cooperação e na construção conjunta com vistas a atingir objetivos comuns. $O$ trabalho de formação na disciplina APS está em acordo com os princípios enfatizados por Delors (1996) em seus Quatro Pilares da Educação. O autor sugere, especialmente, que o método mais adequado para os estudantes aprenderem a viver junto, a viver com os outros, é "a participação em projetos comuns", o que a APS proporciona aos seus estudantes.

Nesse contexto, outra forma de aproximação da disciplina APS com os serviços de APS ocorre semestralmente, através de rodas de conversa com gestores de APS. Elas constituíram mais uma forma de promover o avizinhamento dos estudantes ao cotidiano da profissão de Sanitarista e se configuram na interlocução com gestores e com egressos do curso de Saúde Coletiva exercendo atividade na APS (Albuquerque et al., 2020).

"As rodas de conversa com os gestores acolhendo as experiências que trouxeram, agregou conhecimento" (E35). Muito valorizadas pelos estudantes, as Rodas de Conversa "consistem em um método de participacão coletiva de debate acerca de determinada temática em que e' possível dialogar com os sujeitos, que se expressam e escutam seus pares e a si mesmos por meio do exercício reflexivo" (Moura \& Lima, 2014). Essas ocasiões eram particularmente apreciadas pelos estudantes. Isso ficava evidente pelo seu envolvimento ativo e engajado, revelando sua empatia com os egressos do curso de Saúde Coletiva já trabalhando nos diferentes pontos de atenção à saúde. Ao mesmo tempo em que desvelava a relevância dos assuntos intrinsecamente associados ao seu futuro como Sanitaristas, como enfatizou (E36): "em especial a presença dos egressos de Saúde Coletiva e dos gestores trouxeram uma perspectiva de futuro”.

Ao avaliarem a disciplina, a clareza demonstrada pelos estudantes confirma o estudo de Bartlett (1990, p. 4) no qual a reflexão crítica possibilita "o exame das experiências de ensino como base para avaliação e tomada de decisão e fonte de mudança”. A utilização desse recurso docente contribuiu para a reflexão sobre o desenvolvimento da disciplina, semestre após semestre. Suscitou a reflexão crítica sobre a prática pedagógica, com vistas ao seu aprimoramento gradual. E, ao mesmo tempo, gerou uma sinergia de esforços e de aprendizagem recíprocas (Albuquerque et al., 2020).

\section{Conclusões}

É possível afirmar que a prática desenvolvida nos serviços de Atenção Primária à Saúde promoveu nos estudantes o reforço da sua identidade profissional como Sanitaristas. O sentimento expresso por eles nas avaliações sobre a disciplina Atenção Primária em Saúde sugere que a utilização da Tecnologia Educacional e Social subsidiou o processo de 
ação-reflexão-ação e desencadeou a aceleração de processos complexos de aprendizagem. $\mathrm{Na}$ perspectiva da experiência pedagógica observou-se: a autopercepcão crescente do estudante com a futura profissão; o incremento da compreensão do nexo da teoria com a prática; bem como a percepção da complexidade humana envolvida nos serviços de APS.

Ao longo dos semestres constituiu-se um desafio promover a conjunção da disciplina APS ao mundo real de trabalho no serviço de Atenção Primária à Saúde. Isso demandou um esforço de diálogo e de colaboração recíproca entre instituições e atores sociais tendo em vista o alcance de objetivos pedagógicos comuns. As ferramentas pedagógicas utilizadas refletiram a efetivação de preceitos constantes do Projeto Político Pedagógico do curso de Saúde Coletiva. E, ao mesmo tempo, repercutiram novas concepções e aportes à formação de profissionais de saúde.

Nessa pesquisa a principal contribuição do Estudo de Caso foi a recuperação das vivências dos estudantes e da professora na interação com a realidade construída, conjuntamente, ao longo desses semestres letivos. Isso permitiu retratar o efeito da Tecnologia Educacional e Social aplicada no âmbito da formação do Sanitarista, que é uma nova profissão no campo da saúde coletiva. Possibilitou a compreensão do impacto da TES no exercício da docência, nas parcerias com a rede pública de saúde e na prática profissional na APS. Nesse processo de construção coletiva a avaliação da disciplina feita pelos estudantes no término dos semestres instigou: a aquisição de novas formas de relacionamento com os estudantes e com outros atores sociais, além de agregar novas ideias na elaboração do plano de ensino.

A TES adotada na disciplina, pelas suas características, foi possibilitando uma aproximação contínua de ações pedagógicas com as das Metodologias Ativas, tão indicadas para a área da saúde. Nesse sentido, destacam-se: a vivência direta dos estudantes com o futuro campo de trabalho; a observação de problemas e dificuldades que ali ocorrem e que constituem importante base de reflexão pessoal e coletiva; a clara percepção da relação entre a teoria estudada e a prática observada. Verifica-se o engajamento do estudante em relação a novas aprendizagens, pela compreensão e pelo interesse suscitado pelas vivências. Criam-se, também, sucessivas possibilidades de exercitar a liberdade e a autonomia no processo de tomada de decisões, preparando-os para o exercício da profissão escolhida.

O planejamento, a execução e a avaliação de todo esse conjunto de propósitos e de ações permitem a reflexão e o aprimoramento da disciplina APS numa construção gradativa, como consequência do processo dialético de ação - reflexão - nova ação transformada/ transformadora. Espera-se que os resultados deste estudo venham a contribuir para o estímulo e o fortalecimento de práticas pedagógicas no ensino superior, em especial para a formação do Sanitarista, com caráter inovador.

\section{Referências}

Albuquerque, O. M., Rocha, J. H., Silva, K., Mesquita, L., Azevedo, L., Oliveira, P., Vieira, S., Melis, M. F. \& Rodrigues, C. S. (2018). Uso de tecnologia Social na constituição do conselho gestor de unidade de saúde. RISTI - Revista Ibérica de Sistemas e Tecnologias de Informação, (28), 41-56. 
Albuquerque, O. M., Conceição, M. H., Melis, M. F., Albuquerque, F., Berbel, N. \& Rodrigues, C. (2020). O uso de tecnologia educacional e social na formação de sanitarista. In Fornari, L, Freitas, F., Oliveira, E. S. F., Oliveira, C. \& Costa, A. P. (Eds.). Investigação Qualitativa em Saúde: Avanços e Desafios (v. 3, p. 808-821). Aveiro: Ludomedia.

Bardin, L. (2011). Análise de conteúdo (3. reimp.). Lisboa: Edições, 70.

Bartlett, L. (1990). Teacher development through reflective teaching. In J. C. Richards \& D. Nunan (Eds.). Second language teacher education (p. 202-214). New York: Cambridge University Press.

Brasil (1988). Constituição da República Federativa do Brasil. Brasília. Recuperado em 25 setembro, 2020, em http://www.planalto.gov.br/ccivil _o3/constituicao/ constituicao.htm.

Brasil (1990). Lei $n^{\circ}$ 8.080, de 19 de setembro de 1990. Dispõe sobre as condições para a promoção, proteção e recuperação da saúde, a organização e o funcionamento dos serviços correspondentes e dá outras providências. Recuperado em 25 setembro, 2020, em http://encurtador.com.br/CEHL1.

Brasil (2017). Portaria de Consolidação $n^{0}$ 02, de 28 de setembro de 2017. Aprova a Política Nacional de Atenção Básica. Recuperado em 24 abril, 2020, em http://bvsms.saude.gov.br/bvs/saudelegis/gm/2017/prco002_03_10_2017 Fernanda essa portaria tem versão mais recente com alterações importantes

Brasil (2019). Manual do Sistema com Prontuário Eletrônico do Cidadão PEC: Versão 3.2. Recuperado em 11 outubro 2020, em http://aps.saude.gov.br/ape/esus/ manual/.

Brasil (2019). Projeto Político-Pedagógico. Recuperado em 24 abril, 2020, em http://fce. unb.br/images/documentos/graduacao/saudecoletiva/ppp/ppc_saude_coletiva. pdf.

Corrêa D. S. R. et al. (2019). Movimentos de reforma do sistema de saúde do Distrito Federal: a conversão do modelo assistencial da Atencão Primária à Saúde. Ciência \& Saúde Coletiva, 24(6), 2031-2041.

Costa, S. R. S., Duqueviz, B. C. \& Pedroza, R. L. S. (2015). Tecnologias Digitais como instrumentos mediadores da aprendizagem dos nativos digitais. Revista Quadrimestral da Associação Brasileira de Psicologia Escolar e Educacional, 19(3), 603-610.

Delors, J. (1996). Educação: um tesouro a descobrir: Relatório para a UNESCO da Comissão Internacional sobre Educação para o século XXI (4 ed.). São Paulo: Cortez; MEC; UNESCO, 1996.

Distrito Federal (2017). Protocolo de acesso de atenção primária à saúde do Distrito Federal - PAPS/DF. Recuperado em 24 abril, 2020, em http://www.saude.df.gov. br/wp-conteudo/uploads/2018/o4/Protocolo-Vers\%C3\%A3o-final-aprovada-naCPPAS-10.04-apresentada-ao-gab.pdf. 
Fernandes S, Tareco E., Sistemas de informação como indicadores de qualidade na saúde. Uma revisão de níveis de abordagem RISTI - Revista Ibérica de Sistemas e Tecnologias de Informação, (19), 32-45.

Gil, A. C. (2008). Didática do ensino superior. São Paulo: Atlas.

Guile, D. \& Evans, K. (2010, October). Putting knowledge to work: re-contextualising knowledge through the design and implementation of work-based learning at higher education levels. Recovered in 24 April 2020, on https://s3.eu-west-2. amazonaws.com/assets.creode.advancehe-document-manager/documents/hea/ private/putting-knowledge-to-work_1568037385.pdf.

Januszewski, A. \& Molenda, M. (2008). Definition. In A. Januszewski \& M. Molenda (Eds). Educational technology: a definition with commentary (1st. ed., p. 195-211). New York: Lawrence Earlbaum Associates.

Katajavuori, N., Lindblom-Ylänne, S. \& Hirvonen, J. (2006). The significance of practical training in linking theoretical studies with practice. Higher Education, (51), 439-464.

Lalueza, J. L., Crespo, I., \& Camps, S. (2010). As tecnologias da informação e da comunicação e os processos de desenvolvimento e socialização. Em C. Coll, \& C. Monereo (Orgs.), Psicologia da Educação Virtual: aprender e ensinar com as tecnologias da informação e da comunicação (N. Freitas, Trad., pp. 47-65). Porto Alegre: Artmed.

Lave, J. (1993). The practice of learning. In S. Chaiklin \& J. Lave (Eds.). Understanding practice: perspectives on activity and context (p. 3-32). Cambridge: Cambridge University Press.

Matta, G. C. \& Pontes, A. L. M. (2007). Políticas de saúde: organização e operacionalização do Sistema Único de Saúde. Rio de Janeiro: Fiocruz.

McCrone, T., O’Beirne, C., Sims, D. \& Taylor, A. (2015, November). A review of technical education. Recovered in 24 abril, 2020, on https://www.nfer.ac.uk/media/1584/ aoct01.pdf.

Moura, A. F. \& Lima, M. G. (2014). A reinvenção da roda: roda de Conversa, um instrumento metodológico possível. Revista Temas em Educação (23)1, 98-106.

Pizzinato, A. et al. (2012). A integração ensino-serviço como estratégia na formação profissional para o SUS. Revista Brasileira de Educação Médica 36(1), 170-177.

Portaria $\mathrm{n}^{\mathrm{o}}$ 77, de 14 de fevereiro de 2017 (2017). Estabelece a Política de Atenção Primária à Saúde do Distrito Federal. Diário Oficial do Distrito Federal. Brasília, DF: Secretaria de Estado de Saúde.

Portaria $\mathrm{n}^{0} 78$, de 14 de fevereiro de 2017 (2017). Regulamenta o art. 51 da Portaria $\mathrm{n}^{\circ} 77$, de 2017, para disciplinar o processo de conversão da Atenção Primária à Saúde do Distrito Federal ao modelo a Estratégia Saúde da Família. Diário Oficial do Distrito Federal. Brasília, DF: Secretaria de Estado de Saúde. 
Ramos, M. C., Barros, M. E. B. \& Ferraco, C. E. (2016). As redes cotidianas dos currículos na formacão dos trabalhadores da saúde. In: F. Sodré, M. A. C. Andrade, R. C. D. Lima \& A. C. P. Garcia. Formação em Saúde: práticas e perspectivas no campo da saúde coletiva (p. 30-56). Vitória: EDUFES.

Sant’Anna, I. M. \& Menegolla, M. (1989). Didática: aprender a ensinar [Coleção Escola e Participação]. São Paulo: Loyola.

Silva, O. S. \& Pinto, I. C M. (2013). Construcão da identidade dos atores da saúde coletiva no Brasil: uma revisão da literatura. Interface - Comunicacão, Saúde, Educacão, 17(46), 549-560.

Silva, O. S., Pinto, I. C M. \& Teixeira, C. F. (2018). Identidade profissional e movimentos de emprego de egressos dos cursos de graduacão em Saúde Coletiva. Saúde em Debate, 42(11), 799-808.

Sisson, M. C. (2009). Implantacão de programas e redefinicão de práticas profissionais. Revista Brasileira de Educacão Médica, 33 (Suppl. 1), 92-103.

Stake R. (2000). Case studies. In. Denzin NK e Lincoln YS. Handbook of qualitative research (2nd ed.). California: Sage.

Vendruscolo, C., Prado, M.C. \& Kleba, M. E. (2016). Integracão ensino-servico no âmbito do Programa Nacional de Reorientacão da Formacão Profissional em Saúde. Ciência \& Saúde Coletiva, 21(9), 2949-2960.

Vendruscolo, C., Silva, M. T. \& Silva, M. E. K. (2017). Integração ensino-serviçocomunidade na perspectiva da reorientação da formação em saúde. SUSTINERE, 5(1), 245-259.

Yin, R. K. (2001). Estudo de caso: planejamento e métodos. Porto Alegre: Bookman. 